\title{
Adjuntos modais no conto Grace, de Joyce, e em duas de suas traduções para o português do Brasil
}

Roberta Rego Rodrigues ${ }^{a}$

\begin{abstract}
Resumo
Os adjuntos modais são categorias pertencentes à metafunção interpessoal da linguagem (HALLIDAY, 1994). Em textos literários, podem apontar questões avaliativas por parte do/a narrador/a e das personagens. Este artigo tem por objetivo investigar essas categorias no conto Grace (JOYCE, 2001), em sua reinstanciação interlingual feita por José Roberto O'Shea (JOYCE, 2012) e em sua reinstanciação interlingual produzida por Guilherme da Silva Braga (JOYCE, 2013), ambas para o português do Brasil. Os adjuntos modais dos contos foram anotados mediante o CROSF (FEITOSA, 2006) e quantificados por intermédio do WordSmith Tools (versão 6.0). Os resultados mostram que o texto-fonte apresenta mais adjuntos modais que os textos traduzidos. Também apontam que os adjuntos modais de modo oracional são mais frequentes que os adjuntos modais de comentário nos três contos. Observa-se que os tradutores fazem uso de sua criatividade tradutória ao propor traduções alternativas para os adjuntos modais.
\end{abstract}

Palavras-chave: reinstanciação interlingual; adjuntos modais; contos. 


\section{Introdução}

A interface entre os Estudos da Tradução e a Linguística Sistêmico-Funcional remonta aos anos 1960, tendo como marco a pesquisa basilar de Catford (JESUS, 2012). Há pesquisadores dos Estudos da Tradução que reúnem trabalhos convergentes nessa interface, denominando-os, por exemplo, como Abordagens Discursivas aos Estudos da Tradução (Cf. MUNDAY, 2016). Adoto, neste artigo, a Tradução como Reinstanciação Interlingual (SOUZA, 2010). Em seu trabalho, Souza (2010) não desconsidera a questão de equivalência, porém observa que as pesquisas nessa interface têm privilegiado a hierarquia "realização" em detrimento das outras hierarquias, quais sejam, "instanciação" e "individuação".

Ao basear-se em Malinowski e Firth, quanto aos significados do contexto de situação, e em Sapir e Whorf, quanto às características do contexto de cultura (GHADESSY, 1999), a Linguística Sistêmico-Funcional é uma teoria que proporciona ao/à pesquisador/a instrumentos para descrever línguas em relação tradutória ou não, ao levar em conta estratos linguísticos tanto baixos como altos (HALLIDAY; MATTHIESSEN, 2014). Além disso, essa teoria parte do pressuposto de que a linguagem consiste em uma semiótica social (HALLIDAY, 1978).

A fim de analisar ou descrever a linguagem, Halliday e Matthiessen (2014) indicam as metafunções que são ferramentas proveitosas para averiguar como se dá a construção da experiência humana. Em resumo, a metafunção ideacional refere-se à representação interna e externa dos usuários da língua nos componentes experiencial (i.e., participantes, processos e circunstâncias) e lógico (e.g., expansão, projeção e relações de hipotaxe, parataxe e encaixe). A metafunção interpessoal aponta como esses usuários interagem, e a metafunção textual mostra como os significados ideacionais e interpessoais são organizados estruturalmente (i.e., por intermédio do tema, rema, dado e novo) e semanticamente (i.e., mediante a coesão).

Com enfoque na metafunção interpessoal, este artigo investiga os adjuntos modais (HALLIDAY, 1994) no conto Grace, de James Joyce (2001), na tradução de José Roberto O'Shea (JOYCE, 2012) e na tradução de Guilherme da Silva Braga (JOYCE, 2013). Tem por objetivo verificar como se dá a 
configuração dos Adjuntos Modais de cada texto traduzido em cotejo com o texto-fonte e com os textos traduzidos entre si. trabalho:

As seguintes perguntas de pesquisa norteiam este

(1) Qual é a configuração dos adjuntos modais, considerando cada texto traduzido em relação ao texto-fonte?

(2) Como se configuram os adjuntos modais ao se examinarem as duas traduções?

Aparentemente, os adjuntos modais não constituem categorias pesquisadas com frequência em textos traduzidos. Ademais, ao que parece, esse conto de James Joyce não é ainda objeto de estudo muito frequente na Linguística tampouco na Literatura. Dessarte, espero mostrar, por meio da investigação dos adjuntos modais, como os potenciais de significado do texto-fonte podem ser reinstanciados interlingualmente.

Além desta Introdução, este artigo apresenta uma fundamentação teórica, que trata da tradução como reinstanciação interlingual, da interpessoalidade na linguagem e dos adjuntos modais. Na sequência, expõe a metodologia eleita para viabilizar os resultados e a discussão. Por fim, mostra as considerações finais, expressa um agradecimento e elenca as referências bibliográficas adotadas.

\section{Fundamentação Teórica}

\subsection{Tradução como reinstanciação interlingual}

Ao levar em conta a perspectiva do/a falante ou do/a escritor/a, tendo em vista o plano de conteúdo, as relações interpessoais e experienciais são convertidas em significado. Esse fenômeno linguístico está relacionado com o estrato da semântica. Ainda considerando esse plano, o significado converte-se em fraseio, o que se refere ao estrato da léxicogramática. Ademais, há o plano de expressão, no qual a estratificação ocorre mediante a fonética e a fonologia. A conexão entre esses estratos denomina-se "realização", e tais estratos estão imbricados com o contexto (HALLIDAY; MATTHIESSEN, 2004).

A "instanciação" manifesta-se com a relação entre sistema e texto. Em uma extremidade do continuum, está o 
sistema, que corresponde ao potencial total da língua. Na outra extremidade, encontra-se o texto, que se refere à instância particular. Quando se identifica um tipo textual, move-se da extremidade em que se encontra o texto em direção à outra extremidade na qual está o sistema. Cabe lembrar que textos variam de forma sistemática conforme valores contextuais (HALLIDAY; MATTHIESSEN, 2014).

A "individuação" é uma terceira hierarquia proposta por Martin (2008). Ao lado da "realização" e da "instanciação", a "individuação" concerne "a como os recursos semióticos são distribuídos entre os usuários [da língua] (alocação) e a como tais recursos são usados em comum entre esses usuários (afiliação)"1 (MARTIN, 2009, p. 564). Em outras palavras, a "individuação" investiga a ligação entre o reservatório e o repertório utilizados pelos indivíduos (MARTIN, 2008).

Em resposta a uma perspectiva sistêmico-funcional, que tem frequentemente abordado textos-fontes e seus textos traduzidos sob o viés da "realização", comojá mencionado, Souza (2010) propõe que a tradução seja encarada como reinstanciação interlingual. De acordo com a autora, há reconstrução do potencial de significado por parte do texto traduzido com base em um texto-fonte. Infere-se que exista, nessa reconstrução, uma leitura do texto-fonte que é reinstanciada pelo/a tradutor/a (SOUZA, 2010). Conforme Souza (2010), o/a tradutor/a atua sobre os potenciais de significado, os quais são identificados por meio das escolhas feitas por ele/ela no texto traduzido. Essas escolhas convergem entre os dois sistemas que são criados pelo/a tradutor/a segundo seus repertórios (SOUZA, 2010). Ao considerar que a tradução é uma renegociação de significados, Souza (2010) estabelece diálogos com teóricos dos Estudos da Tradução, como Lefevere (1992a, 1992b), Robinson (1991) e Venuti (2009). A autora enfoca a pesquisa feita por este último teórico, cuja descrição dos três contextos constitutivos do textofonte é necessária para que tais contextos sejam reelaborados no texto traduzido. Esses três contextos tratam de relações

${ }^{1}$ Minha tradução de: "[...] how semiotic resources are distributed among users (allocation) and how these resources a re deployed to c o m m u e (affiliation)." intertextuais, quais sejam, do texto estrangeiro com outros textos; do texto estrangeiro com a tradução; e da tradução com outros textos (VENUTI, 2009 apud SOUZA, 2010). Por fim, a autora lança mão de recursos da valoração (appraisal), segundo Martin e White (2005), a fim de verificar como os textos-fontes podem ser reinstanciados. 
A seguir, expõem-se algumas categorias da metafunção interpessoal da linguagem.

\subsection{Interpessoalidade na linguagem}

Interagir com outros indivíduos constitui um dos principais objetivos da comunicação humana quando estabelecemos e mantemos vínculos sociopessoais adequados aos/às usuários/as da língua. A linguagem é uma via de mão dupla, visto que trocamos significados com os indivíduos para atingir propósitos nas interações. Essencialmente, as interações se manifestam por meio de orações declarativas, interrogativas e imperativas. A fim de pesquisá-las, tem-se de levar em consideração o modo oracional, a modalidade, a avaliação (evaluation) e a negociação (THOMPSON, 2014).

Consideremos o exemplo a seguir. Trata-se de uma sentença retirada do conto Graça, de James Joyce (2013), com tradução de Guilherme da Silva Braga.

\section{Exemplo 1:}

Graças a esses dois artigos de vestuário, dizia, um homem podia estar sempre elegante (JOYCE, 2013).

O exemplo 1 encontra-se em uma passagem do conto que mostra características do protagonista Sr. Kernan. A sentença pode ser reestruturada da seguinte maneira: “Graças a esses dois artigos de vestuário, um homem podia estar sempre elegante, dizia." "Dizia" é uma oração cujo modo oracional é o sujeito gramatical elíptico, Sr. Kernan, e o finito, que indica o tempo verbal pretérito imperfeito. No caso dessa oração, o finito está fundido com o predicador. De acordo com Alves, Lacerda e Rodrigues (2006), tal fusão é mais recorrente na língua portuguesa do que na língua inglesa. Além disso, em "Graças a esses dois artigos de vestuário, um homem podia estar sempre elegante," o modo oracional é o sujeito gramatical expresso "um homem", o finito modal, "podia" e o adjunto modal de modo oracional de usualidade, "sempre". Este último se apresenta de forma descontínua (HALLIDAY; MATTHIESSEN, 2014), visto que não vem imediatamente após o sujeito gramatical e o finito modal. Ademais, esse adjunto modal contribui para a modalização da oração assim como o finito modal que diz respeito à probabilidade de 
um homem estar elegante. Além disso, "Graças a esses dois artigos de vestuário" é um adjunto que, juntamente a "estar" e "elegante", forma o resíduo. Em uma perspectiva experiencial da linguagem, tal adjunto seria uma circunstância de causa do tipo razão (HALLIDAY; MATTHIESSEN, 2004).

Thompson (2014) refere-se à avaliação (evaluation) de maneira análoga à valoração (appraisal), conforme teorizada por Martin e White (2005). O autor destaca que a valoração é verificada por intermédio de escolhas lexicais em detrimento de estruturas gramaticais, que são escassas do ponto de vista da função essencialmente avaliativa. Thompson (2014) aponta que a valoração (appraisal) está presente no cerne semântico de qualquer texto. O autor também aponta que o/a pesquisador/a não deveria prescindir de questões valorativas na investigação de significados interpessoais. Ademais, o sistema de valoração (appraisal) pressupõe os sistemas de atitude, comprometimento e gradação, que reúnem valores semântico-discursivos passíveis de serem identificados em vários textos (MARTIN; WHITE, 2005).

De modo semelhante a Martin (1992), Thompson (2014) salienta que a negociação se relaciona com os papéis de fala (speech roles). O bem trocado entre os/as usuários/as da língua pode ser do tipo "bens e serviços" e do tipo "informação" (THOMPSON, 2014). Existem fundamentalmente quatro papéis de fala ou quatro funções de fala (speech functions), quais sejam, fornecer informação, solicitar informação, fornecer bens e serviços e solicitar bens e serviços (THOMPSON, 2014). Respectivamente, ao fornecer bens e serviços e informações, temos uma oferta e uma declaração e, ao solicitar bens e serviços e informações, temos uma ordem e uma pergunta (THOMPSON, 2014). Ofertas e ordens referem-se a propostas, enquanto declarações e perguntas aludem a proposições (HALLIDAY; MATTHIESSEN, 2004). Thompson (2014) assinala que os papéis de fala podem ser mais complexos, como, por exemplo, uma oração declarativa que desempenha uma função de oração interrogativa.

Em seguida, são considerados os adjuntos modais.

\subsection{Adjuntos modais}

Adjuntos modais consistem em grupos adverbiais e sintagmas preposicionados que apresentam força interpessoal 
(HALLIDAY, 1994; THOMPSON, 2014). Segundo esses autores, eles podem ser de modo oracional ou de comentário. Halliday (1994) observa que tanto o primeiro como o segundo podem manifestar-se em diferentes posições dentro da oração, quais sejam, temática, neutra e como um adendo (afterthought). Ademais, Thompson (2014) cita exemplos de adjuntos modais de modo oracional desempenhando diferentes papéis: "nunca" (never) está relacionado com a polaridade; "talvez" (maybe) diz respeito à modalidade; e "já" (already) refere-se ao tempo verbal. Apesar de Thompson (2014) afirmar que "nunca" (never) está atrelado à polaridade, Halliday (1994) considera que "nunca" (never) é um adjunto modal de modo oracional de usualidade. Conforme Halliday (1994) e Thompson (2014), os adjuntos modais de comentário são, com frequência, assinalados na linguagem escrita mediante vírgulas e exprimem particularidades de posicionamento do/a falante em relação à proposição como um todo. Além disso, Halliday (1994) observa que os adjuntos modais estão estritamente ligados ao sistema de modo oracional, apesar de os adjuntos modais de modo oracional estarem mais vinculados a esse sistema em comparação aos adjuntos modais de comentário. Em seguida, são expostos os quadros 1 e 2: o quadro 1 abrange os adjuntos modais de modo oracional, e o quadro 2 abarca os adjuntos modais de comentário.

Quadro 1: Adjuntos modais de modo oracional de acordo com Halliday (1994, p. 82-83) com tradução para o português brasileiro de Bernardino (2012, p. 468).

\begin{tabular}{|c|c|}
\hline TIPO & EXEMPLOS \\
\hline Polaridade & não, sim, sim também (so) \\
\hline Probabilidade & provavelmente, possivelmente, certamente, talvez \\
\hline Usualidade & usualmente, às vezes, sempre, nunca, jamais, raramente \\
\hline Inclinação & $\begin{array}{l}\text { voluntariamente, prontamente, felizmente, certamente, } \\
\text { facilmente }\end{array}$ \\
\hline Obrigação & definitivamente, absolutamente, a todo custo \\
\hline Teтро & ainda, já, uma vez, logo, apenas \\
\hline Tipicidade & $\begin{array}{l}\text { ocasionalmente, geralmente, regularmente, principalmente, } \\
\text { na maioria das vezes }\end{array}$ \\
\hline Obviedade & é claro, certamente, obviamente, claramente \\
\hline Intensidade & $\begin{array}{l}\text { somente, simplesmente, meramente, até mesmo, realmente, de } \\
\text { fato }\end{array}$ \\
\hline Grau & $\begin{array}{l}\text { quase, aproximadamente, escassamente, dificilmente, } \\
\text { absolutamente, totalmente, completamente, inteiramente }\end{array}$ \\
\hline
\end{tabular}
Fonte: RODRIGUES; TOZZI, 2017, p. 131-132. 
Consoante Halliday (1994), como pode ser verificado pelo quadro 1, existem dez tipos de adjunto modal de modo oracional. Para um detalhamento desses adjuntos, Thompson (2014) sugere consultar Halliday e Matthiessen (2014, p. 188-189).

Quadro 2: Adjuntos modais de comentário de acordo com Halliday (1994, p. 49) com tradução para o português brasileiro de Alves, Lacerda e Rodrigues (2006, p. 18).

\begin{tabular}{|c|c|c|}
\hline TIPO & SIGNIFICADO & EXEMPLOS \\
\hline Opinião & Acho & $\begin{array}{l}\text { em minha opinião, } \\
\text { pessoalmente }\end{array}$ \\
\hline Admissão & Admito & $\begin{array}{c}\text { francamente, sinceramente, } \\
\text { para lhe dizer a verdade }\end{array}$ \\
\hline Persuasão & Garanto a você & $\begin{array}{c}\text { honestamente, realmente, } \\
\text { com seriedade }\end{array}$ \\
\hline Requerimento & Peço-lhe & por favor \\
\hline Preunção & Presumo & $\begin{array}{l}\text { evidentemente, } \\
\text { aparentemente, } \\
\text { presumivelmente }\end{array}$ \\
\hline "Desejabilidade" & Quão desejável? & $\begin{array}{l}\text { in/felizmente, para meu } \\
\text { deleite, esperançosamente }\end{array}$ \\
\hline "Fidedignidade" & Quão confiável? & $\begin{array}{l}\text { provisoriamente, } \\
\text { primeiramente }\end{array}$ \\
\hline Validaçãao & Quão válido? & $\begin{array}{c}\text { em geral, como um todo, } \\
\text { estritamente falando, em } \\
\text { principio }\end{array}$ \\
\hline Avaliação & Quão sensato? & $\begin{array}{l}\text { im/prudentemente, } \\
\text { compreensivelmente }\end{array}$ \\
\hline Previsão & Quão esperado? & $\begin{array}{c}\text { surpreendentemente, como } \\
\text { esperado, por acaso }\end{array}$ \\
\hline
\end{tabular}

Fonte: RODRIGUES; TOZZI, 2017, p. 132-133.

De acordo com Halliday (1994), como mostrado no quadro 2, há dez tipos de adjunto modal de comentário. Para mais especificidade (delicacy, em inglês) dessas categorias, Thompson (2014) recomenda buscar informação em Halliday e Matthiessen (2014, p. 191).

Anteriormente, foram realizados dois trabalhos. No primeiro, sob a perspectiva dos Estudos da Tradução baseados em corpus e da Linguística Sistêmico-Funcional, Rodrigues (2005) investigou a estrutura temática da novela 
A hora da estrela (LISPECTOR, 1999) e da novela The hour of the star com tradução de Giovanni Pontiero (LISPECTOR, 1992). Além de outros focos de análise, foram pesquisados os temas interpessoais juntamente com os temas ideacionais participantes e os temas ideacionais participantes elípticos, relativos ao narrador Rodrigo S. M. e à protagonista Macabéa. Foi utilizada a ferramenta Concord do software WordSmith Tools (versão 3.0) para fazer um levantamento daquelas orações já etiquetadas com temas interpessoais que incluíssem o narrador e a protagonista. Dentre os tipos de temas interpessoais como, por exemplo, vocativos e finitos, constatou-se que, nessa correlação, os adjuntos modais são os mais frequentes em ambos os textos. Portanto, conforme Rodrigues (2005), a interpessoalidade temática nesse corpus está bem destacada em função da recorrência de adjuntos modais que imprimem ao narrador e à protagonista recursos valorativos.

No segundo, sob a égide das Abordagens Discursivas aos Estudos da Tradução (Cf. MUNDAY, 2016), Rodrigues e Tozzi (2017) investigaram os adjuntos modais (HALLIDAY, 1994) no conto A pair of silk stockings, de Kate Chopin (1994), e em duas de suas traduções para o português do Brasil, uma produzida por Márcia Knop (CHOPIN, 2011) e a outra por Henrique Vieira Tozzi (CHOPIN, 2017). Foi observado que essas categorias linguísticas se tornam relevantes para identificar traços de posicionamento do/a narrador/a e das personagens. Nesse trabalho, houve a anotação de adjuntos modais de modo oracional e de comentário, cuja quantificação foi feita por intermédio da ferramenta Concord do software WordSmith Tools (versão 4.0). Percebeu-se que os adjuntos modais de modo oracional são mais recorrentes que os adjuntos modais de comentário nesses textos literários traduzidos. Verificouse que os adjuntos modais de modo oracional ocorrem mais constantemente nas traduções do que no texto-fonte. Observouse que Tozzi (CHOPIN, 2017) tende a tematizar os adjuntos modais, o que não é visto com tanta frequência em Knop (CHOPIN, 2011).

Baseando-se nas teorias utilizadas, a seguir, são mostrados os procedimentos de análise, bem como algumas características do corpus selecionado. 


\section{Metodologia}

\subsection{0 corpus}

Foram selecionados o conto Grace em inglês irlandês do livro Dubliners, de James Joyce (2001), uma reinstanciação interlingual desse conto, de José Roberto O'Shea (JOYCE, 2012), e uma reinstanciação interlingual de Guilherme da Silva Braga (JOYCE, 2013), ambas para o português do Brasil. Os contos perfazem aproximadamente 24.000 palavras. Grace conta a história do Sr. Kernan, pai de família, caixeiro-viajante decadente e alcoolista. Seus amigos, ao perceber a derrocada do Sr. Kernan, reúnem-se para planejar um retiro espiritual para o amigo, que, na verdade, é um protestante que "se convertera" ao catolicismo quando do seu casamento com a Sra. Kernan. Grace é um conto repleto de diálogos que abordam assuntos corriqueiros, bem como questões religiosas, principalmente, no tocante ao catolicismo e ao protestantismo.

Segundo O'Shea (2012), Dubliners é perpassado pela epifania, que é uma característica distintiva da escrita joyceana. Conforme o tradutor, essa epifania atravessa a obra literária joyceana como um todo, porém é mais acentuada em Dubliners.

Ao comentar sobre a segunda tradução de Dubliners, O'Shea (2012, p. 14) constata que "pôde levar a termo centenas de retoques, ajustes e importantes correções que resultaram em uma nova tradução". Em um intervalo de quase vinte anos entre sua primeira e segunda tradução, O'Shea (2012) observa que se tornou um tradutor literário mais experiente, o que $o$ motivou a traduzir Dubliners novamente.

Em entrevista concedida à editora LP\&M, de Porto Alegre, Braga (2012, n.p.) aponta o que sobressai no estilo de Joyce em Dubliners, destacando o "minimalismo dos acontecimentos que movem as narrativas. São quase sempre acontecimentos muito pequenos e aparentemente triviais que funcionam como mote ou como resolução da narrativa." Essa observação de Braga (2012, n.p.) está condizente com o que O'Shea (2012) afirma sobre epifania nessa obra de Joyce.

\subsection{Procedimentos de análise}

Os contos foram digitalizados, revisados e convertidos para arquivos com extensão doc. Foram feitas anotações de 
corpus (KÜBLER; ZINMEISTER, 2015), que são métodos de acrescentar classificações linguísticas aos textos em formato eletrônico. Mais especificamente, o CROSF, ou seja, o Código de Rotulação Sistêmico-Funcional, (FEITOSA, 2006) foi utilizado como ferramenta de anotação dos adjuntos modais do corpus.

O CROSF foi originalmente elaborado para a análise de temas de textos, porém possibilita também a investigação textual sob o prisma das metafunções ideacional e interpessoal (FEITOSA, 2006). É constituído de sete dígitos numéricos, que são dispostos entre parênteses angulares, o que oferece presteza à anotação do corpus e facilita a visualização do texto depois da classificação (FEITOSA, 2006). A seguir, são mostrados os quadros 3 e 4 (RODRIGUES, 2017) com os rótulos numéricos para cada instância de adjunto modal.

Quadro 3: Rótulos para os adjuntos modais de modo oracional

\begin{tabular}{cc}
\hline Adjunto modal de modo oracional & Rótulo \\
\hline Polaridade & $<0020411>$ \\
Probabilidade & $<0020412>$ \\
Usualidade & $<0020413>$ \\
Inclinação & $<0020414>$ \\
Obrigação & $<0020415>$ \\
Tempo & $<0020421>$ \\
Tipicidade & $<0020422>$ \\
Obviedade & $<0020431>$ \\
Intensidade & $<0020432>$ \\
Grau & $<0020433>$ \\
\hline
\end{tabular}

Fonte: ELABORAÇÃO PRÓPRIA.

Feitosa (2006) elaborou o CROSF fundamentando-se, sobretudo, em Halliday (1994). A título de ilustração, o rótulo <0020433> pode ser visto do seguinte modo: os primeiros dois dígitos com 0 são relativos à estrutura temática; o quarto dígito com 0 refere-se à modalização e à modulação e não foi levado em conta na anotação do corpus; o dígito 2 mostra que a metafunção é a interpessoal; o dígito 4 aponta que a categoria em questão é um adjunto modal de modo oracional; os dígitos 33 indicam que o adjunto modal de modo oracional é de grau. 
Quadro 4: Rótulos para os adjuntos modais de comentário

\begin{tabular}{c|c}
\hline Adjunto modal de comentário & Rótulo \\
\hline Opinião & $<0020611>$ \\
Admissão & $<0020612>$ \\
Persuasão & $<0020613>$ \\
Requerimento & $<0020614>$ \\
Presunção & $<0020616>$ \\
"Desejabilidade" & $<0020617>$ \\
"Fidedignidade" & $<0020621>$ \\
Validação & $<0020622>$ \\
Avaliação & $<0020631>$ \\
Previśa & $<0020632>$ \\
\hline Fonte: ELABORAÇ̃̃o PRÓPRIA. &
\end{tabular}

O quadro 4 (RODRIGUES, 2017) mostra os adjuntos modais de comentário, conforme Halliday (1994), e seus rótulos, sob a perspectiva de Feitosa (2006), que se fundamentou neste último autor para desenvolvê-los, como já mencionado. Cumpre relembrar que esses rótulos são resultados de uma adaptação que tem o propósito de atender aos objetivos do presente trabalho. Ademais, Halliday e Matthiessen (2014, p. 188-189, 191 apud THOMPSON, 2014) sugerem uma categorização bem mais específica para os adjuntos modais de modo oracional e de comentário, como já apontado anteriormente. Entretanto, no tocante à anotação do corpus, penso que as categorias de adjuntos modais, como defendidas por Halliday (1994), sejam mais funcionais para o presente artigo.

Os adjuntos modais foram quantificados no WordSmith Tools (versão 6.0) por intermédio da ferramenta Concord, que, além de fazer a contagem dos dados, mostra todas as sentenças em que cada adjunto modal está re/instanciado. Cumpre recordar que os textos têm de apresentar o formato $t x t$ a fim de que o referido software os detecte (RODRIGUES, 2017).

A seção seguinte traz os resultados e discussão deste artigo.

\section{Resultados e Discussão}

Esta seção mostra a quantificação dos adjuntos modais e o que os dados quantitativos podem revelar. Cumpre salientar que os números são absolutos. $O$ texto-fonte de Joyce é abreviado como TF; o texto traduzido 1 de O'Shea, como RI1 (Reinstanciação Interlingual 1); e, por fim, o texto traduzido 2 de Braga, como RI2 (Reinstanciação Interlingual 2). Observemos as tabelas 1 e 2. 
Tabela 1: Adjuntos modais de modo oracional no texto-fonte e nas reinstanciações interlinguais

\begin{tabular}{c|c|c|c}
\hline & $\begin{array}{c}\text { TF } \\
\text { (Joyce) }\end{array}$ & $\begin{array}{c}\text { RI1 } \\
\text { (O'Shea) }\end{array}$ & $\begin{array}{c}\text { RI2 } \\
\text { (Braga) }\end{array}$ \\
\hline Polaridade & 101 & 104 & 101 \\
Probabilidade & 1 & 4 & 6 \\
Usualidade & 22 & 16 & 18 \\
Inclinação & 3 & 2 & - \\
Obrigação & - & 1 & - \\
Tempo & 16 & 16 & 14 \\
Tipicidade & 6 & 4 & 5 \\
Obviedade & 10 & 10 & 14 \\
Intensidade & 18 & 24 & 18 \\
Grau & 65 & 44 & 42 \\
\hline TOTAL & 242 & 225 & 218 \\
\hline
\end{tabular}

Fonte: ELABORAÇÃO PRÓPRIA.

Tabela 2: Adjuntos modais de comentário no texto-fonte e nas reinstanciações interlinguais

\begin{tabular}{c|c|c|c}
\hline & $\begin{array}{c}\text { TF } \\
\text { (Joyce) }\end{array}$ & $\begin{array}{c}\text { RI1 } \\
\text { (O'Shea) }\end{array}$ & $\begin{array}{c}\text { RI2 } \\
\text { (Braga) }\end{array}$ \\
\hline Opinião & - & 1 & - \\
Admissão & 2 & 1 & 1 \\
Persuasão & - & - & - \\
Requerimento & - & 1 & 1 \\
Presunção & - & - & - \\
"Desejabilidade" & 4 & 4 & 4 \\
"Fidedignidade" & - & - & - \\
Validação & - & - & - \\
Avaliação & 3 & 4 & - \\
Previs̃á & 1 & - & 1 \\
\hline TOTAL & 10 & 11 & 7 \\
\hline Fonte: ELABORAÇão PRÓPRIA. & & &
\end{tabular}

Considerando as tabelas 1 e 2, o TF apresenta 252 adjuntos modais; o RI1 236 adjuntos modais e, finalmente, o RI2 possui 225 adjuntos modais. Tais dados mostram que a quantidade desses adjuntos é abundante no corpus em questão. Isso pode ser relacionado com os resultados de Rodrigues (2005), em que os adjuntos modais funcionando como temas interpessoais são os mais recorrentes em comparação a outras categorias da metafunção interpessoal em posição temática. No entanto, ao examinarmos as tabelas 1 e 2 , podemos observar que os adjuntos modais de modo oracional são bem mais frequentes que os adjuntos modais de comentário. Tal dado 
se coaduna com os resultados de Rodrigues e Tozzi (2017), em que os primeiros adjuntos são também mais recorrentes que os segundos adjuntos. Isso indica que os modos oracionais "acumulam" mais significados interpessoais, ou seja, além dos sujeitos gramaticais e dos finitos (modais), há re/instanciação de adjuntos modais. Como Rodrigues (2005) e Rodrigues e Tozzi (2017) apontam, o estudo desses adjuntos também é relevante para questões de narratividade, uma vez que esses elementos manifestam traços valorativos do/a narrador/a e das personagens.

Ao contrário de Rodrigues e Tozzi (2017), no qual a quantidade de adjuntos modais é mais elevada nas traduções que no texto-fonte, como mostram as tabelas 1 e 2 , podemos perceber que a quantidade de adjuntos modais é maior no TF que nas RI1 e RI2. Isso demonstra que o TF solicita mais recursos interpessoais mediante os adjuntos modais em comparação às RI1 e RI2. Entretanto, no que concerne aos adjuntos modais de modo oracional, todos os contos apresentam os de polaridade e os de grau como os mais recorrentes. A polaridade refere-se à oposição entre o positivo e o negativo e está presente nos papéis de fala (HALLIDAY; MATTHIESSEN, 2014). O uso massivo de adjuntos modais de modo oracional de polaridade no corpus está atrelado aos vários diálogos dos contos em que os polos "sim" e "não" são demandados por meio de proposições e propostas. Ademais, o uso bastante recorrente de adjuntos modais de modo oracional de grau está ligado à intensificação de itens lexicais no TF, na RI1 e na RI2. Além disso, no tocante aos adjuntos modais de comentário, o de "desejabilidade" é o mais frequente no corpus, o que denota "quão in/desejável" (HALLIDAY, 1994) o posicionamento do/a narrador/a e/ou das personagens pode ser.

Ao compararmos a RI1 com o TF, podemos notar que os adjuntos modais de modo oracional de polaridade, probabilidade, obrigação e intensidade são mais frequentes na RIl que no TF. Além disso, podemos verificar que os adjuntos modais de modo oracional de usualidade, inclinação, tipicidade e grau são menos recorrentes na RI1 em cotejo com o TF. Ademais, os adjuntos modais de modo oracional de tempo e obviedade apresentam o mesmo número de ocorrências em ambos os textos. No que tange aos adjuntos modais de comentário, há mais ocorrências de opinião, requerimento e avaliação na RI1 que no TF. Os adjuntos modais de comentário de admissão e previsão são menos frequentes na RI1 que no TF. Finalmente, os adjuntos modais de comentário de persuasão, presunção, "fidedignidade" e validação não se manifestam nesses dois textos. 
Ao cotejarmos a RI2 com o TF, os adjuntos modais de modo oracional de probabilidade e obviedade estão mais presentes na RI2 que no TF. Podemos verificar que os adjuntos modais de modo oracional de usualidade, tempo, tipicidade e grau ocorrem em menor grau na RI2 em comparação com o TF. O adjunto modal de modo oracional de inclinação não apresenta ocorrências nesse texto traduzido. Além disso, o número de ocorrências dos adjuntos modais de modo oracional de polaridade e intensidade é igual em ambos os textos. Não há ocorrências do adjunto modal de modo oracional de obrigação na RI2 e nem no TF. No que concerne aos adjuntos modais de comentário, o de requerimento é mais frequente na RI2 que no TF. O adjunto modal de comentário de admissão ocorre menos nessa reinstanciação interlingual em cotejo com o texto-fonte e, apesar de o TF apresentar ocorrências de adjunto modal de comentário de avaliação, a RI2 não manifesta nenhuma ocorrência desse adjunto modal. Por fim, os adjuntos modais de comentário de opinião, persuasão, presunção, "fidedignidade" e validação apresentam frequência nula nesses dois textos.

Ao compararmos a RI2 com a RI1, a reinstanciação interlingual de Braga (RI2) tem mais ocorrências de adjuntos modais de modo oracional de probabilidade, de usualidade, de tipicidade e de obviedade, em cotejo com a reinstanciação interlingual de O'Shea (RI1). No entanto, ao contrário da RI1, a RI2 não apresenta os adjuntos modais de modo oracional de inclinação e de obrigação. Na RI1, os adjuntos modais de modo oracional de polaridade, tempo, intensidade e grau são mais frequentes que na RI2. Ademais, a RI2 possui mais ocorrências de adjuntos modais de comentário de previsão em comparação com a tradução de O'Shea (RI1). Embora esta apresente uma ocorrência de adjunto modal de comentário de opinião e quatro ocorrências de adjunto modal de comentário de avaliação, a RI2 não os manifesta. Ademais, ambas as reinstanciações interlinguais estão quites em relação ao número de ocorrências de adjuntos modais de comentário de admissão, requerimento e "desejabilidade". Finalmente, na RI2 e na RI1, não existem ocorrências dos seguintes adjuntos modais de comentário: persuasão, presunção, "fidedignidade" e validação.

Vejamos, logo em seguida, os exemplos 2, 3 e 4. Os adjuntos modais estão em itálico, acompanhados dos seus respectivos rótulos. 


\section{Exemplo 2:}

TF (Joyce):

TWO GENTLEMEN who were in the lavatory at the time tried to lift him up: but he was quite <0020433> helpless. He lay curled up at the foot of the stairs down which he had fallen. They succeeded in turning him over (JOYCE, 2001).

\section{RI1 (O'Shea):}

DOIS CAVALHEIROS que estavam no banheiro naquele momento tentaram levantá-lo: mas ele estava inerte. Jazia encolhido ao pé da escada na qual havia tombado. Conseguiram virá-lo de barriga para cima (JOYCE, 2012).

\section{RI2 (Braga):}

Dois cavalheiros que na hora estavam no lavatório ajudaramno a levantar, mas não <0020411> havia muito <0020433> o que fazer. Ele ficou encolhido no pé da escada de onde havia caído. Os homens só <0020432> conseguiram virá-lo (JOYCE, 2013).

O exemplo 2 refere-se ao início dos contos e mostra o $\mathrm{Sr}$. Kernan sendo acudido por dois homens. Podemos notar que o trecho do TF instancia um adjunto modal de modo oracional de grau, qual seja, quite. O'Shea não reinstancia esse adjunto modal ao passo que Braga o faz, de alguma forma, ao optar por um adjunto modal de modo oracional de polaridade, isto é, "não", que se relaciona ao adjunto modal de modo oracional de grau, "muito". Ademais, diferentemente do TF e da RI, Braga acrescenta um adjunto modal de modo oracional de intensidade, ou seja, "só" que sinaliza uma contraexpectativa (HALLIDAY; MATTHIESSEN, 2014). O exemplo 2 aponta que os trechos da RI1 e da RI2 estão em relação de tradução com o TF, mas isso não significa que os tradutores tenham de reinstanciar palavra-por-palavra. Eles podem usar sua criatividade (SOUZA, 2010) e sua experiência como tradutores literários a fim de fazer escolhas tradutórias que não sejam muito literais, mas sim aceitáveis para o público-alvo.

\section{Exemplo 3:}

\section{TF (Joyce):}

The man, without answering, began to twirl the ends of his moustache. He made light of his accident. It was nothing, 
he said: only <0020432> a little accident. He spoke very $<0020433>$ thickly (JOYCE, 2001).

\section{RI1 (O'Shea):}

O homem, sem responder, começou a enroscar a ponta do bigode. Tentou minimizar o acidente. Aquilo fora coisa à toa, ele disse: apenas $<0020432>$ um pequeno acidente. Falava com uma voz engrolada (JOYCE, 2012).

\section{RI2 (Braga):}

O homem, sem responder, começou a torcer as pontas do bigode. Fez pouco-caso do acidente. Não <0020411> era nada, disse: apenas <0020432> um pequeno acidente. A fala do homem estava pastosa (JOYCE, 2013).

No exemplo 3, que trata mais uma vez de uma passagem com o Sr. Kernan, podemos verificar que only é reinstanciado na RIl e na RI2 como "apenas". Além disso, observam-se adjuntos modais de modo oracional de intensidade. Ademais, o adjunto modal de modo oracional de grau very não é reinstanciado pelos tradutores. Como podemos observar na tabela 1 , o TF apresenta mais ocorrências desse adjunto modal em cotejo com a RI1 e a RI2. É provável que traduções literárias na nossa língua não favoreçam a utilização muito recorrente desse tipo de adjunto. Pode ser também uma questão do sistema linguístico do português do Brasil, que não faz uso frequente desse adjunto modal em textos literários. Além disso, Braga utiliza outra vez um adjunto modal de modo oracional de polaridade, isto é, “não", em "Não era nada [...]”. Essa negação não está instanciada explicitamente com um adjunto modal no TF, como podemos observar em It was nothing, e O'Shea reinstancia essa oração do inglês para o português como "Aquilo fora coisa à toa [...]", sem usar um adjunto modal de modo oracional de polaridade negativa.

\section{Exemplo 4:}

\section{TF (Joyce):}

The narrative made Mr Kernan indignant. He was keenly $<0020433>$ conscious of his citizenship, wished to live with his city on terms mutually <0020433> honourable and resented any affront put upon him by those whom he called country bumpkins (JOYCE, 2001). 


\section{RI1 (O'Shea):}

O relato deixou Mr Kernan indignado. Era muito <0020433> cioso de sua cidadania, pretendia ter com a cidade um relacionamento mutuamente <0020433> honrado e não $<0020411>$ admitia afrontas feitas por indivíduos que a seu ver $<0020611>$ não <0020411> passavam de caipiras (JOYCE, 2012).

\section{RI2 (Braga):}

A narrativa deixou o sr. Kernan indignado. Tinha plena consciência da própria cidadania, desejava viver na cidade em termos honrosos e ressentia qualquer afronta causada pelas pessoas a quem chamava de grosseirões caipiras (JOYCE, 2013).

O trecho do TF, no exemplo 4, que trata de um momento de indignação do Sr. Kernan, apresenta dois adjuntos modais de modo oracional de grau, quais sejam, keenly e mutually. Em uma perspectiva experiencial da linguagem, esses adjuntos seriam circunstâncias de modo de qualidade (HALLIDAY; MATTHIESSEN, 2004). Porém, nesse trecho, eles funcionam como intensificadores (MARTIN; WHITE, 2005; HALLIDAY; MATTHIESSEN, 2014) dos itens lexicais conscious e honourable. Ademais, O'Shea reinstancia esses adjuntos como "muito" e "mutuamente" e acrescenta dois adjuntos modais de modo oracional de polaridade, isto é, "não". Por exemplo, em "não admitia afrontas [...]", O'Shea explicita o teor negativo de resented any affront ao optar por esse adjunto modal. Além disso, esse tradutor faz uso de um adjunto modal de comentário de opinião, ou seja, "a seu ver", que não está instanciado no TF. Em uma visão experiencial da linguagem, esse adjunto modal seria uma circunstância de ângulo (HALLIDAY; MATTHIESSEN, 2004). Podemos dizer que esse adjunto modal "reforça" a opinião do Sr. Kernan, mesmo que essa personagem esteja sendo referida na terceira pessoa do discurso. De modo interessante, Braga não reinstancia nenhum adjunto modal do TF no exemplo 4. Porém, a título de exemplificação, Braga usa o item lexical "plena", que apresenta força de intensificação. Dessarte, Braga oferece uma alternativa de tradução para o adjunto modal de modo oracional de grau keenly, do TF.

Procedemos, em seguida, às considerações finais deste artigo. 


\section{Considerações Finais}

Este artigo alcançou os objetivos de verificar como se configuram os adjuntos modais de cada texto traduzido em comparação com o texto-fonte e das reinstanciações interlinguais reciprocamente.

A anotação e posterior quantificação dos adjuntos modais possibilitou o seu rastreamento ao longo dos contos, o que provém de uma visão desses textos como um todo do ponto de vista dessas categorias. A anotação e posterior quantificação dos adjuntos modais em Grace (JOYCE, 2001), em Graça, com tradução de José Roberto O'Shea (JOYCE, 2012) e em Graça, traduzido por Guilherme da Silva Braga (JOYCE, 2013), também, demonstrou que há uma grande variedade dessas categorias no corpus. Em termos gerais, os adjuntos modais são mais frequentes no texto-fonte que nos textos traduzidos, o que se opõe a Rodrigues e Tozzi (2017), no qual tais categorias se manifestam amiúde nas reinstanciações interlinguais. Ademais, os adjuntos modais de modo oracional são mais recorrentes que os adjuntos modais de comentário nos três contos analisados, o que vai ao encontro do trabalho de Rodrigues e Tozzi (2017). Assim, diferentes estudos de caso sobre temas semelhantes propiciam uma discussão proveitosa e uma ampliação do conhecimento sobre os fenômenos linguísticos em questão. Além disso, em comparação a Braga, O'Shea faz mais uso de adjuntos modais, tanto de modo oracional como de comentário, o que demonstra, sob essa perspectiva, que a interpessoalidade do/a narrador/a e das personagens está mais evidente na RI1 que na RI2.

Como visto na seção 4, relativa aos resultados e discussão, considerando os dados de forma global, existem adjuntos modais que são recorrentes nos três contos e, levando em conta os dados de forma local, podemos observar que essas categorias são re/instanciadas conforme escolhas linguísticas do escritor e dos tradutores. O texto-fonte serve de guia para os tradutores, mas isso não significa que os tradutores não possam tomar decisões tradutórias que sejam mais distantes do texto-fonte. Nos exemplos 2, 3 e 4 da referida seção, podemos constatar que nem todos os adjuntos modais do texto-fonte foram reinstanciados por adjuntos modais nos textos traduzidos. Isso comprova ainda mais que a equivalência não se dá somente 
palavra-por-palavra e que, conforme defende Souza (2010), os tradutores têm também o respaldo de sua criatividade de escolha dos fenômenos linguísticos que desejam reinstanciar.

\section{Agradecimento}

Agradeço ao doutorando Cliver Dias por ocasião da discussão sobre a anotação do corpus.

\section{REFERÊNCIAS}

ALVES, D.; LACERDA, P. B. G.; RODRIGUES, R. R. A metafunção interpessoal em duas propagandas turísticas institucionais. Polissema, Porto, v. 6, p. 7-39, 2006.

BERNARDINO, C. Artigo acadêmico: a construção de significados interpessoais. RBLA, Belo Horizonte, v. 12, n. 3 , p. 463-492, 2012.

BRAGA, G. S. O tradutor de Dublinenses fala sobre tradução e James Joyce. Entrevista concedida a LP\&M EDITORES, 2012. Disponível em: https://www.lpm.com.br/site/default.asp?Tr oncoID $=805133 \& S e c a o I D=816261 \& S u b s e c a o I D=618848 \& T e m$ plate $=$. .artigosnoticias/user_exibir.asp\&ID $=636311$. Acesso em: 8 out. 2018.

CHOPIN, K. A pair of silk stockings. In: . The awakening and selected short stories. Project Gutenberg, 1994. (Conto primeiramente publicado em 1897). Disponível em: http://www.dominiopublico.gov. br/download/texto/gu000160.pdf. Acesso em: 16 mai. 2016.

. Um par de meias de seda. Tradução de Márcia Knop. In: VIÉGAS-FARIA, B.; CARDOSO, B. M.; BROSE, E. R. Z. (org.). Kate Chopin: contos traduzidos e comentados. Estudos literários e humanidades médicas. Porto Alegre: Casa Editorial Luminara, 2011.

. Uma meia de seda. Tradução de Henrique Vieira Tozzi. Mafuá, Florianópolis, v. 27, p. 126-141, 2017.

FEITOSA, M. P. Developing and applying CROSF: a numeric code proposed for corpora annotation, based on Halliday's Systemic Functional Grammar. In: INTERNATIONAL SYSTEMIC 
FUNCTIONAL CONGRESS, 33, 2006, São Paulo. Proceedings... São Paulo: PUC, 2006. p. 1130-1150.

GHADESSY, M. (ed.). Text and context in functional linguistics. Amsterdam: John Benjamins, 1999.

HALLIDAY, M. A. K. Language as a social semiotic: the social interpretation of language and meaning. London: Edward Arnold, 1978.

. An introduction to functional grammar. 2 ed. London/ New York: Edward Arnold, 1994.

HALLIDAY, M. A. K.; MATTHIESSEN, C. M. I. M. An introduction to functional grammar. 3 ed. London/New York: Routledge, 2004.

. Halliday's introduction to functional grammar. $4 \mathrm{ed}$. London/New York: Routledge, 2014.

JESUS, S. M. Estudos sistêmicos-funcionais da tradução. Dominios de Lingu@gem, Uberlândia, v. 6, n. 1, p. 285-301, 2012.

JOYCE, J. Grace. In: Dubliners. Ware: Wordsworth Editions, 2001. (Obra literária primeiramente publicada em 1914).

JOYCE, J. Graça. In: . Dublinenses. Tradução de José Roberto O'Shea. São Paulo: Editora Hedra, 2012.

JOYCE, J. Graça. In: . Dublinenses. Tradução de Guilherme da Silva Braga. Porto Alegre: L\&PM Editores, 2013.

KÜBLER, S.; ZINMEISTER, H. Corpus Linguistics and linguistically annotated corpora. London/New Delhi/New York/ Sydney: Bloomsbury, 2015.

LEFEVERE, A. Translation, rewriting, and the manipulation of literary fame. London/New York: Routledge, 1992a.

. (ed.) Translation history culture: a source book. London/ New York: Routledge, 1992 b.

LISPECTOR, C. The hour of the star. Tradução de Giovanni Pontiero. New York: New Directions Book, 1992. 
. A hora da estrela. Rio de Janeiro: Rocco, 1999. (Novela primeiramente publicada em 1977).

MARTIN, J. R. English text: system and structure. Amsterdam/ Philadelphia: John Benjamins, 1992.

. Tenderness: realisation and instantiation in a Botswanan town. In: NØRGAARD, Nina (ed.) Systemic Functional Linguistics in Use. Odense Working Papers in Language and Communication v. 29, p. 30-62, 2008.

Realisation, instantiation and individuation: some thoughts on identity in youth justice conferencing. D.E.L.T.A., São Paulo, v. 25, ESPECIAL, p. 549-583, 2009.

MARTIN, J. R.; WHITE, P. R. R. The language of evaluation: appraisal in English. Basingstoke/New York: Palgrave Macmillan, 2005.

MUNDAY, J. Discourse and register analysis approaches. In: Introducing Translation Studies: Theories and Applications. 4 ed. London/New York: Routledge, 2016. p. 141-168.

O'SHEA, J. R. Introdução. In: JOYCE, J. Dublinenses. Tradução de José Roberto O’Shea. São Paulo: Editora Hedra, 2012. p. 7-17.

ROBINSON, D. The translator's turn. Baltimore/London: Johns Hopkins University Press, 1991.

RODRIGUES, R. R. A organização temática em A hora da estrela e The hour of the star. 2005. 171f. Dissertação (Mestrado em Linguística Aplicada) - Faculdade de Letras, Universidade Federal de Minas Gerais. Belo Horizonte, 2005.

RODRIGUES, R. R. Valoração em contos de James Joyce e em duas de suas traduções para o português do Brasil sob a ótica dos Adjuntos Modais. 2017. 16f. Projeto de Pesquisa (Pós-doutorado em Linguística Aplicada) - Centro de Letras e Comunicação, Universidade Federal de Pelotas. Pelotas, 2017.

RODRIGUES, R. R.; TOZZI, H. V. Adjuntos modais de textos literários em relação de tradução. TRANSLATIO, Porto Alegre, n. 14, p. 126-141, dez. 2017. 
SOUZA, L. M. F. Interlingual re-instantiation: a model for a new and more comprehensive systemic functional perspective on translation. 2010. 339f. Tese (Doutorado em Língua Inglesa) Centro de Comunicação e Expressão, Universidade Federal de Santa Catarina. Florianópolis, 2010.

THOMPSON, G. Introducing functional grammar. 3 ed. London/ New York: Routledge, 2014.

VENUTI, L. Translation, intertextuality, interpretation. Romance Studies, v. 27, n. 3, p. 157-173, 2009.

\begin{abstract}
Modal adjuncts in the short story Grace, by Joyce, and in two of its translations into Brazilian Portuguese
\end{abstract}

Modal adjuncts belong to interpersonal metafunction (HALLIDAY, 1994). They can point to the narrator's and the characters' evaluation in literary texts. This paper aims to delve into these categories in the short story Grace (JOYCE, 2001) and in two of its interlingual reinstantiations into Brazilian Portuguese, one by José Roberto O'Shea (JOYCE, 2012), and the other one by Guilherme da Silva Braga (JOYCE, 2013). Modal adjuncts of the short stories were annotated by using CROSF (FEITOSA, 2006), and quantified on WordSmith Tools (version 6.0). The results point out that the source text has more modal adjuncts if compared to the translations. In addition, they show that mood adjuncts are more frequent than comment adjuncts in the corpus. It can be noticed that the translators use their translational creativity when they propose alternative translations to modal adjuncts.

Keywords: interlingual reinstantiation, modal adjuncts, short stories. 